\title{
Seleção de diretores de escolas públicas e avaliação do desempenho do candidato
}

\author{
Recruitment of public school principals \\ and evaluation of the candidate's performance
}

\section{Selección de directores de escuelas públicas y evaluación del desempeño del candidato}

\begin{abstract}
RESUMO: O trabalho aborda os requisitos na legislação de oito municípios do estado do Rio de Janeiro sobre a avaliação de desempenho dos candidatos à direção de escolas públicas. Plano de gestão, cursos e currículo são os requisitos nos documentos analisados. A avaliação de desempenho dos candidatos é regulamentada conforme o momento político de cada ente federado e sinaliza as infidelidades normativas e a forma elástica como se apropriam da legislação nacional, estabelecendo um cenário multifacetado sobre os sentidos atribuídos à gestão democrática e ao perfil do diretor desejado.
\end{abstract}

Palavras-chave: Plano Nacional de Educação. Gestão Democrática. Gestor escolar. Desempenho.

\begin{abstract}
The paper deals with the requirements in the legislation of eight municipalities of the state of Rio de Janeiro on performance assessment of candidates for the head of public schools. Management plan, courses and curriculum are the required documents to be reviewed. The performance of the candidates is regulated according to the political moment of each federated entity and indicates the normative deceitfulness and the elastic way in which they adapt the national legislation, establishing a multifaceted scenario
\end{abstract}

* Doutora em Educação. Pós-doutorado em Administração Pública pela FGV-RJ e pós-doutorado em Ciências da Educação pela Universidade do Minho, Portugal. E-mail: danielapatti.ufrj@gmail.com. 
on the directions assigned to the democratic management and the profile of the intended director.

Keywords: National Education Plan. Democratic management. School manager. Performance.

RESUMEN: El trabajo aborda los requisitos en la legislación de ocho municipios del estado de Rio de Janeiro sobre la evaluación de desempeño de los candidatos a dirección de las escuelas públicas. Plan de gestión, cursos y currículo son los requisitos en los documentos analizados. La evaluación de desempeño de los candidatos está regulada según el momento político de cada ente federado y señala las infidelidades normativas y la forma elástica como seapropian delalegislación nacional, estableciendo un escenario multifacético sobre los sentidos atribuidos a la gestión democrática y al perfil del director deseado.

Palabras clave: Plan Nacional de Educación. Gestión Democrática. Gestor escolar. Desempeño.

\section{Introdução}

$\mathrm{E}$ ste artigo parte do pressuposto de que a eleição de diretores de escolas públicas é um dos critérios fundamentais para a consolidação de uma gestão democrática. A Constituição Federal (BRASIL, 1988) e a LDB 9.394 (BRASIL, 1996) estabeleceram que o ensino público será ministrado com base em uma gestão democrática e o Plano Nacional de Educação (PNE/ BRASIL, 2014) definiu que os entes federados aprovem legislação específica que promova e discipline a gestão democrática da educação pública para seus sistemas de ensino. A seleção de diretores para as escolas públicas deverá estar associada a critérios técnicos de mérito e desempenho e à consulta pública à comunidade escolar, no âmbito das escolas públicas. No entanto, face à enorme diversidade do País, o cenário para aferir o mérito e o desempenho do candidato é multifacetado e irá levar em conta, dentre outros fatores, a história de cada ente federado, as correlações de força nos poderes Executivo e Legislativo, a participação da comunidade escolar no processo e, não menos importante, o perfil profissional do diretor desejado pela rede pública de educação. Configura-se, assim, um campo fértil de pesquisa e análise dos sentidos atribuídos à gestão democrática da educação e dos significados sobre o que é mérito e como se afere o desempenho dos candidatos à direção das escolas. 
Face ao cenário complexo da regulamentação da gestão democrática nos estados e municípios brasileiros, o presente artigo aborda como a categoria desempenho foi ressignificada na legislação específica de oito municípios do estado do Rio de Janeiro. Mendonça (2001) destaca que "os mecanismos de provimento do cargo de diretor escolar são reveladores das concepções de gestão democrática adotadas pelos sistemas de ensino" (pg. 88). Conforme o autor, em relação às leis específicas sobre gestão democrática, "esses instrumentos legais constituem-se como manifestação legislativa mais completa do entendimento das autoridades sobre a maneira pela qual a norma constitucional se aplica ao sistema público de ensino de sua alçada" (pg. 86). Os textos políticos são o resultado de disputas e acordos, pois os grupos que atuam dentro dos diferentes lugares da produção de textos competem para controlar as representações da política.

Tendo em vista que a aprovação da quase totalidade dos planos de educação dos municípios do estado do Rio de Janeiro ocorreu em 2015 ${ }^{1}$, o prazo para aprovação da legislação que regulamente a gestão democrática e o processo de seleção de diretores de escola já expirou. Acerca da concepção de gestão democrática, concordamos com Souza (2009, pg.125), quando afirma que

a gestão democrática deve ser entendida como um processo político no qual as pessoas que atuam na/sobre a escola identificam problemas, discutem, deliberam e planejam, encaminham, acompanham, controlam e avaliam o conjunto das ações voltadas ao desenvolvimento da própria escola na busca da solução daqueles problemas.

É um processo que, segundo o autor, tem como base a participação efetiva de todos os segmentos da comunidade escolar, o respeito às normas coletivamente construídas para os processos de tomada de decisões e, ainda, a garantia de amplo acesso às informações aos sujeitos da escola.

As agendas que influenciaram a elaboração do PNE (BRASIL, 2014) resultaram no texto final da Lei que serve de plano de orientação para os estados e municípios, tendo em vista a necessidade de alinhamento dos planos educacionais dos entes federados às metas e estratégias estabelecidas no Plano Nacional. Entretanto, os atores envolvidos no debate e elaboração dos planos no âmbito dos estados e municípios ressignificam e hibridizam, produzindo uma apropriação mais ou menos elástica da lei nacional na consolidação das legislações próprias. No contexto da aprovação dos mecanismos que irão assegurar a gestão democrática nas escolas públicas, os poderes Executivo e Legislativo têm papel fundamental na sanção da legislação que irá materializar questões que abarcam a gestão democrática, tais como o processo de seleção de diretores de escolas, composição dos conselhos escolares e grêmios estudantis, associação de pais e responsáveis, dentre outros aspectos.

Na perspectiva de analisar o texto político produzido por diferentes entes federados, apresentamos como a categoria desempenho, prevista no PNE, foi ressignificada na 
legislação específica de oito municípios do estado do Rio de Janeiro: Duque de Caxias, Valença, Sumidouro, Niterói, Iguaba Grande, Carmo, Aperibé e Rio de Janeiro. Após busca realizada nos sites das prefeituras, câmaras de vereadores e secretarias municipais de Educação dos 92 municípios do estado do Rio de Janeiro, no período de março a dezembro de 2017, essas oito cidades foram selecionadas, tendo em vista que foram localizadas legislações aprovadas que regulamentam o processo de seleção dos diretores de escolas públicas. Compreendemos, conforme Lima (2011, p. 170), que o estudo das diferentes legislações não esgota a compreensão das realidades, mas são importantes fontes de pesquisa. A análise das diferentes fontes, mesmo que com hierarquias e alcances distintos, e o seu cotejo, de forma a identificar possíveis consistências, inconsistências, articulações, desarticulações e infidelidades normativas é indispensável, "no sentido de considerar distintos centros de decisão, variadas políticas e orientações, distintas recepções e recontextualizações" (LIMA, 2011, pg. 170).

Em relação à meta 19 do PNE e suas estratégias, o legislador, ao produzir o texto da política, oscilou entre dois termos jurídico-normativos: no artigo 9º menciona a aprovação de lei específica, mas na estratégia 19.1 determina a aprovação de legislação específica. Compreendemos que lei é o conjunto de normas dispondo sobre determinada matéria e legislação é o conjunto de leis que vigoram no ordenamento jurídico, logo, é formada pela reunião dos códigos, das leis especiais, das normas, decretos, portarias, resoluções, ou seja, toda a normativa em vigor. Nesse sentido, acreditamos que há uma espécie de escala que mede a democracia conforme a gestão democrática é disciplinada ou regulamentada pelo ente federado. Caso a regulamentação do processo de seleção de diretores ocorra por Decreto do prefeito, Resolução ou Portaria do secretário de educação ou através de Lei, a participação da comunidade escolar e local e dos destinatários da política será diferente. As portarias, decretos e resoluções emanam do Poder Executivo e podem ser revogadas a qualquer momento, dando fragilidade ao processo democrático. Uma lei, aprovada na Câmara de Vereadores e Assembleia Legislativa, demanda debates, audiências públicas e possibilita maior participação popular, portanto, podemos inferir se tratar de mecanismo mais democrático e participativo. Não que tenhamos garantias de que os poderes legislativos municipais e estaduais estejam blindados de interferências do Executivo ou mesmo privatistas. Mendonça (2001, pg. 98) nos ajuda nessa reflexão ao afirmar que "a posição hierárquica do instrumento legal utilizado na institucionalização de diretrizes políticas na área educacional parece ser um fator indicador da menor ou maior perenidade dessas diretrizes".

Por conta disso, os contextos de influência que irão permear a produção dos textos legais também serão diferentes, de modo que vozes serão mais ou menos silenciadas bem como as possibilidades de revogação da norma serão mais ou menos democráticas e participativas, promovendo uma escala no que diz respeito à participação dos destinatários da política na sua elaboração e aprovação. 


\section{Gestão democrática: a agenda na aprovação do PNE 2014-2024}

Conforme Gomes (2015), a proposta do PNE enviada pelo Poder Executivo à Câmara dos Deputados abordava a gestão democrática em dois dispositivos. Constava como uma das diretrizes previstas no Artigo $2^{\underline{0}}$ do Projeto de Lei nº 8.035/2010, além do Art. 9º , que determinava aos estados, ao Distrito Federal e aos municípios a atribuição de aprovar leis específicas, disciplinando a gestão democrática da educação em seus respectivos âmbitos de atuação. Concedia, para tanto, o prazo de um ano a partir da publicação da lei. No anexo do documento foi inserida a Meta 19, que visava garantir, mediante lei específica aprovada no âmbito dos entes federados, a nomeação comissionada de diretores de escola vinculada a critérios técnicos de mérito e desempenho e à participação da comunidade escolar. O texto era acompanhado por duas estratégias - o menor número entre o conjunto de metas que o PNE abrangia. Uma que estabelecia prioridade no repasse de transferências voluntárias para os entes federados que aprovassem lei específica disciplinando a nomeação de diretores a partir de critérios técnicos de mérito e desempenho e com a participação da comunidade escolar. A segunda estratégia tratava da realização de prova nacional para subsidiar o provimento dos cargos de diretores escolares. As duas foram mantidas no texto final.

Segundo Gomes (2015), na primeira fase de tramitação do Projeto de Lei $\mathrm{n}^{\underline{0}}$ 8.035/2010 na Câmara dos Deputados foram apresentadas 2.906 emendas, um recorde em se tratando de uma proposição legislativa ordinária. Dessas, cerca de 3\% (74 emendas) buscavam incidir sobre a Meta 19 e suas estratégias. No Senado, ampliou-se para dois anos o prazo dos entes federados para o cumprimento do disposto no Art. $9^{\circ}$, substituindo-se a aprovação de leis específicas pelo encaminhamento de projeto de lei ao Poder Legislativo local. No retorno à Câmara, segundo a autora, "considerou-se que o comando havia perdido muito de sua força impositiva, e o texto final combinou a proposta de leis específicas com o prazo de dois anos para aprovação ou adequação de legislação local sobre o tema" (pg. 149). Por fim, finaliza a autora, o texto preservou a ideia de que a gestão democrática deveria ser associada a critérios técnicos de mérito e desempenho e explicitou a proposta de consulta pública à comunidade escolar. Porém, como foi suprimida a referência à direção escolar, não ficou explícito em que aspectos da gestão democrática tais critérios de consulta pública devem ser aplicados (pg. 149). À seleção para diretores de escola deveriam estar vinculados critérios técnicos de mérito e desempenho sem a menção à eleição direta. Segundo Gomes (2015 pg146), o tema foi ofuscado pelo debate sobre o financiamento da educação, avaliação e outros que se sobrepuseram na agenda e não foi realizada nenhuma audiência pública com o tema gestão democrática. 
No caso dos entes federados, espera-se que a elaboração e aprovação dos planos de educação ocorram por meio de diferentes percursos em contextos diversos, conforme o movimento político de cada estado ou município, que inclui: a realização ou não de audiências públicas, consultas à comunidade, a atuação do corpo técnico do Poder Executivo e a composição do Poder Legislativo. Destacamos, entretanto, que nem sempre a legislação local está alinhada à legislação nacional. Nesse aspecto, Lima (2011) afirma que a produção de uma regra não garante, obrigatoriamente e automaticamente, sua reprodução por parte de quem age e toma decisões. Segundo o autor, por vezes, podem constituir bons indicadores das dificuldades ou incapacidades de resolver problemas e de concretizar mudanças decretadas, procurando compensar o déficit de mudança através de recursos retóricos e discursos doutrinais ou da reelaboração de certas regras (p.174).

\section{Avaliação do candidato à direção de escola: o que revelam as legislações}

Face à complexidade das distintas realidades dos municípios brasileiros, não há consenso acerca de como avaliar o desempenho dos candidatos à direção das escolas públicas. Adicionalmente, em vista da autonomia dos entes federados, os sentidos, as ressignificações e os hibridismos nas legislações revelam características das redes de educação, das culturas postas em cena, além das histórias e trajetórias políticas de cada município ou estado brasileiro.

O estado do Rio de Janeiro é composto por 92 municípios, dividido em oito Regiões de Governo: Metropolitana, Noroeste Fluminense, Norte Fluminense, Baixadas Litorâneas, Serrana, Centro-Sul Fluminense, Médio Paraíba e Costa Verde. Com exceção do próprio estado e do município do Rio de Janeiro, capital fluminense, os demais 91 municípios aprovaram seus planos de educação. Em sua análise, Amaral (2016) indicou que o prazo para regulamentação da gestão democrática nos planos de educação dos municípios fluminenses oscilou entre seis meses a dois anos, dependendo do ente federado. Para a elaboração deste artigo, buscamos, no período de março a dezembro de 2017, as regulamentações da gestão democrática nos endereços eletrônicos das 91 prefeituras e respectivas secretarias de educação, além do site das câmaras de vereadores e do Ministério Público estadual. Face ao reduzido número de documentos, inferimos dois caminhos: ou a regulamentação ainda não foi aprovada ou não está disponível para consulta pública nos sites visitados.

Apresentamos, no Quadro 1, uma síntese das informações coletadas nos documentos que regulamentam a gestão democrática na rede estadual de educação e nos oito municípios em que a legislação está disponível para consulta e que contemplam os modelos de avaliação de desempenho dos candidatos à direção de escolas públicas. 


\begin{tabular}{|c|c|c|}
\hline Município & $\begin{array}{l}\text { Meta/estratégia sobre gestão democrática no } \\
\text { Plano estadual/municipal de educação }\end{array}$ & $\begin{array}{l}\text { Mecanismo de } \\
\text { regulamentação }\end{array}$ \\
\hline $\begin{array}{l}\text { Rio de Janeiro } \\
\text { (rede estadual) }\end{array}$ & Plano não aprovado & $\begin{array}{l}\text { Lei } 7.299 \text { de } 3 \text { de } \\
\text { junho de } 2016 .\end{array}$ \\
\hline Duque de Caxias & $\begin{array}{l}\text { Meta } 15 \text { dispõe sobre a regulamentação de lei orgânica } \\
\text { municipal que trata das eleições diretas para diretores } \\
\text { das unidades escolares. }\end{array}$ & $\begin{array}{l}\text { Lei N. } 2864 \text { de } 1 \\
\text { de novembro de } \\
2017 .\end{array}$ \\
\hline Valença & $\begin{array}{l}\text { Meta 19: assegurar condições, no prazo de } 2 \text { (dois) anos, } \\
\text { para efetivação da gestão democrática da educação no } \\
\text { âmbito das escolas públicas. }\end{array}$ & $\begin{array}{l}\text { Resolução N. 003/ } \\
\text { SME/2015. }\end{array}$ \\
\hline Sumidouro & $\begin{array}{l}\text { Estratégia 19.1- Instituir a eleição direta para o cargo } \\
\text { de gestor, nas escolas públicas municipais. Cita o } \\
\text { Anteprojeto de lei 13/2016 - art. } 4^{\circ} \text { - seleção mediante } \\
\text { critérios de competência técnica e legitimação adicional } \\
\text { pela comunidade escolar (eleição); Art. 9o - prova de } \\
\text { competência técnica, eleição e nomeação pelo Executivo. }\end{array}$ & $\begin{array}{l}\text { Lei N. } 1.142 \text { de } 15 \\
\text { de junho de } 2016 .\end{array}$ \\
\hline Niterói & $\begin{array}{l}\text { Estratégia } 3.3 \text { - garantir o fortalecimento, por parte } \\
\text { do poder público, da consulta à comunidade escolar } \\
\text { nos procedimentos para o provimento dos cargos de } \\
\text { direção das unidades escolares, de maneira direta, livre } \\
\text { e permitindo apenas uma recondução, para garantir a } \\
\text { democratização do processo. }\end{array}$ & $\begin{array}{l}\text { Edital N. 006/2017 } \\
\text { da Fundação } \\
\text { Municipal de } \\
\text { Educação de } \\
\text { Niterói. }\end{array}$ \\
\hline Iguaba Grande & $\begin{array}{l}\text { Estratégia 19.7- Desenvolver programas de formação de } \\
\text { gestores, candidatos ao cargo, estabelecendo consulta } \\
\text { para a troca de direção a cada } 2 \text { anos, garantindo } \\
\text { formação para os candidatos a partir do } 1^{\circ} \text { semestre de } \\
\text { 2016, para início do processo de consulta iniciando a } \\
\text { Gestão democrática em } 2017 \text {. }\end{array}$ & $\begin{array}{l}\text { Autógrafo ao } \\
\text { Projeto de Lei } \\
\text { N. 016/2016 } \\
\text { aprovado em } 2 \text { de } \\
\text { agosto de } 2016 .\end{array}$ \\
\hline Carmo & $\begin{array}{l}\text { Não apresenta informações sobre o processo de seleção } \\
\text { de diretores. }\end{array}$ & $\begin{array}{l}\text { Lei N. } 1.852 \text { de } 25 \\
\text { de novembro de } \\
2016 .\end{array}$ \\
\hline Aperibé & $\begin{array}{l}\text { Meta 19. Fornecer cursos de capacitação e formação para } \\
\text { diretores e gestores escolares, bem como eleições para } \\
\text { diretores, a fim de não ocorrer nomeação política. }\end{array}$ & $\begin{array}{l}\text { Lei N. } 667 \text { de } 28 \\
\text { de outubro de } \\
2016 .\end{array}$ \\
\hline Rio de Janeiro & Plano não aprovado. & $\begin{array}{l}\text { Resolução SME } \\
\text { N. } 20 \text { de } 29 \text { de } \\
\text { setembro de } 2017 .\end{array}$ \\
\hline Cabo Frio & $\begin{array}{l}\text { Estratégia 19.9. Assegurar a consulta à comunidade } \\
\text { escolar para escolha das direções das escolas da Rede } \\
\text { Municipal, conforme previsto na legislação em vigor. }\end{array}$ & $\begin{array}{l}\text { Lei } 2.902 \text { de } 7 \\
\text { de novembro de } \\
2017 .\end{array}$ \\
\hline
\end{tabular}

Quadro 1. Fonte: legislações estadual e municipais. Elaborado pela autora.

Inicialmente, indagamos se podemos considerar o desempenho do candidato uma categoria fundamental no seu processo seletivo. Afinal, como aferir esse desempenho? Quais critérios definir? Acreditamos que esse não é um território de consenso. Luck (2011) destaca que na literatura não há estudos demonstrativos da efetividade das políticas de seleção de diretores, independentemente da modalidade de seleção adotada. 
Paro (1992; 2006) argumenta que inúmeros estudos e pesquisas têm demonstrado que o que se exige do diretor, em termos técnicos, em comparação com o que o bom professor detém, é ínfimo. Segundo o autor, somente os que veem no diretor um gerente de fábrica podem reivindicar um componente técnico que não seja o próprio conhecimento de educador.

O município de Duque de Caxias (RJ) regulamentou a gestão democrática, inicialmente, através do Decreto 6.542, de 11/5/2015, que dispõe sobre eleições para diretores e vice-diretores das unidades escolares do município. No entanto, em novembro de 2017 aprovou a Lei N. 2.864, que dispõe sobre a gestão democrática da educação pública municipal. Dois procedimentos legais distintos em dois contextos políticos distintos, tendo em vista que em 2016 houve eleições municipais que mudaram a configuração político-partidária de Duque de Caxias². A legislação aprovada em 2017 determina que o diretor escolhido deverá participar de curso de gestão oferecido pela Secretaria e Educação, entregar currículo e apresentar projeto de gestão para análise e homologação por uma comissão técnica (DUQUE DE CAXIAS, 2017).

Já o município de Valença estabeleceu normas para eleição de diretor e diretor adjunto das escolas/creches da rede municipal de ensino através da Resolução n. 003/2015, de 5/11/2015, da Secretaria Municipal de Educação. Conforme o documento, é exigida do candidato a frequência de curso para qualificação do exercício da função para a qual vier a ser convocado, além da apresentação de plano de gestão para implementação das ações junto à comunidade (VALENÇA, 2015).

A Secretaria Municipal de Educação do Rio de Janeiro aprovou, em 29 de setembro de 2017, a Resolução n. 20, que dispõe sobre o processo de seleção de gestores das unidades escolares da rede pública do sistema municipal de ensino da cidade do Rio de Janeiro $^{3}$. O documento não prevê critérios de avaliação do desempenho do candidato à função de diretor de escola, mas determina que nos três primeiros meses do mandato o ocupante do cargo de diretor deverá coordenar o processo de construção de um projeto de gestão, em conjunto com a comunidade escolar, a ser aprovado pela Secretaria Municipal de Educação e implementado na unidade escolar (RIO DE JANEIRO, 2017).

Sumidouro regulamentou a gestão democrática através da Lei 1.142, de 15/6/2016. A legislação determina que ainda serão publicadas diretrizes em documento específico acerca do processo seletivo que constará de "provas de competência técnica" para avaliar o desempenho do candidato (SUMIDOURO, 2016).

A Fundação Municipal de Educação de Niterói publicou, em novembro de 2017, o Edital 006/2017, que dispõe sobre o processo de consulta direta à comunidade escolar para a função de diretor e diretor adjunto das unidades de educação da rede municipal. O edital determina a exigência de apresentação de um plano de gestão a ser desenvolvido na unidade escolar (FUNDAÇÃO MUNICIPAL DE EDUCAÇÃO DE NITERÓI, 2017). 
Iguaba Grande aprovou, em agosto de 2016, a Lei 016/2016 sobre o processo de gestão democrática nas escolas municipais. A legislação não define critérios de avaliação do desempenho dos candidatos (IGUABA GRANDE, 2016).

O município de Carmo aprovou, em 25 de setembro de 2016, a Lei N. 1.852, que dispõe sobre a instituição da gestão democrática na rede municipal de ensino. $\mathrm{O}$ candidato à direção das escolas deverá apresentar um plano de gestão, que será avaliado pela comissão eleitoral a ser nomeada pela Secretaria de Educação e composta por professores, responsáveis e aluno maior de 16 anos (CARMO, 2016).

Aperibé aprovou, em 28 de outubro de 2016, a Lei N. 667, que dispõe sobre a gestão democrática do ensino público municipal. A escolha dos diretores ocorrerá por meio de seleção mediante critérios de competência técnica ainda não discriminados (APERIBÉ, 2016).

Observamos que os municípios de Iguaba Grande, Sumidouro e Aperibé não definiram na legislação como ocorrerá o processo de seleção dos diretores. Mesmo com duas legislações aprovadas - o Plano Municipal de Educação e a legislação que dispõe sobre a gestão democrática do ensino, os três municípios ainda terão que deliberar acerca do processo de seleção dos diretores e dos critérios para avaliar o desempenho dos candidatos. Nesse sentido, novas arenas de disputa irão se instalar e prorroga-se, dessa maneira, um passo importante pra a materialização da gestão democrática, que é a eleição dos diretores.

A apresentação de um plano de gestão é elemento comum para as redes de educação estadual, de Carmo (2016), Niterói (2017), Duque de Caxias (2017), Valença (2015) e Rio de Janeiro (2017). A diferença entre essas legislações está na regulamentação carioca, que, diferentemente das demais, prevê a construção do plano de gestão em diálogo com a comunidade escolar após a posse do diretor. Podemos inferir que esse mecanismo é mais participativo, tendo em vista que o candidato não irá chegar com um manual pronto para os problemas da escola, mas irá debater com a comunidade escolar seus anseios, desejos, planos e problemas. Entretanto, a Secretaria de Educação irá supervisionar a construção do plano nas escolas, o que sugere um movimento de descentralização centralizadora, tendo em vista que não ficaram claros, na legislação, o perfil da equipe fiscalizadora e o grau de possíveis interferências desta equipe na construção do plano.

Tanto Duque de Caxias como Valença incluíram a exigência da realização de um curso a ser oferecido pelas respectivas secretarias de Educação, porém não ficou especificado se a aprovação nesse curso é requisito para a nomeação na função, o que pode criar um mecanismo que dificulte ou mesmo impeça que esse candidato assuma a função, mesmo depois de consultada a comunidade. Duque de Caxias ainda exige a apresentação do currículo, sem, contudo, discriminar como ele será avaliado e quais critérios serão utilizados para pontuar a trajetória do candidato. Por fim, destacamos um elemento curioso na legislação de Carmo, ao definir que a comissão eleitoral que irá coordenar o processo 
seletivo e avaliar, inclusive, o plano de gestão do candidato será composta por um aluno maior de 16 anos. Se a expectativa é que o aluno complete o ensino fundamental com 15 anos, o número de alunos com 16 anos ou mais na rede municipal tende a ser muito reduzido, restando, principalmente, os matriculados na educação de jovens e adultos.

Acerca dos mecanismos presentes para avaliação do desempenho, como o candidato à direção foi submetido previamente a um concurso público para as redes municipais, indagamos se faria sentido submetê-lo a uma nova prova para a função gestora. A apresentação de um plano de gestão como requisito prévio e sem debate ou discussão com a comunidade pouco contribui para a democratização do processo, ao se aproximar de uma proposta esvaziada que pode ser descontextualizada, tendo em vista que a comunidade escolar não participou do debate. Adicionalmente, ao instituir a submissão e aprovação desse plano por uma banca, há pouca clareza do que será avaliado e pontuado no plano. Nesse sentido, é necessário refletir sobre quais os sentidos da apresentação de um projeto antecipado e, também, como criar estratégias para que esse projeto seja construído coletivamente em um período de tempo que permita sua execução durante o mandato, como sugere a legislação do município do Rio de Janeiro. A análise do perfil do candidato através do currículo permite diferentes possibilidades de leitura e avaliação, tendo em vista que as percepções do perfil podem contemplar uma trajetória acadêmica, executiva, sindical, docente. Logo, o que será levado em conta na pontuação e avaliação desse candidato irá se aproximar ou afastar do perfil desejado por quem irá coordenar o processo. Afinal, como afirmado por Carvalho (2012), nenhum modo de escolha para diretores de escola é neutro.

\section{Considerações finais}

A identidade dos diretores, conforme Silva (2011, p.212), é o conjunto das representações colocadas em circulação tanto pelos discursos oficiais quanto pelo discurso dos próprios, que são relativos aos modos de ser e agir do gestor da escola no exercício de suas funções. Nesse sentido, indagamos se as exigências postas nas legislações sobre o desempenho dos candidatos a diretor estão em conformidade com uma perspectiva de gestão democrática tendo em vista que o resultado do desempenho depende do indivíduo, de suas características e trajetórias. Na perspectiva da análise do desempenho no processo seletivo, o perfil do diretor desejado pela rede e pela comunidade será componente fundamental, dependendo dos encaminhamentos que cada rede implementar, assim como a identidade do diretor que irá assumir a gestão da escola pública. A elaboração, aprovação e execução de um plano de gestão para as escolas públicas evidenciam marcas presentes na esfera pública a partir da década de 1990, como descrito por Branco (2014). 
Algumas questões que consideramos relevantes encerram o presente texto e permitem novas reflexões e investigações. Qual o sentido de um plano de gestão estéril, padronizado e sem diálogo com a comunidade? Soa mais como uma proposta tutelada em que o candidato à gestão parte do princípio do que a escola necessita sem, contudo, ouvir as vozes da comunidade escolar e dos destinatários das políticas. Como e por quem será feita a supervisão desse plano de gestão posto em cena nas escolas? Quais os conteúdos dos cursos de gestão e quem irá oferecê-los, já que estão vinculados à nomeação e posse dos candidatos? Que modelo de gestão será pautado de forma compulsória aos gestores que dependem da aprovação no curso para serem nomeados?

Ainda em terreno frágil, a gestão democrática nas escolas públicas oscila entre a seleção na perspectiva da construção de uma identidade para o diretor, ora como um líder, ora como um gestor que promova uma atuação colegiada e participativa, dando voz a todos e todas que constroem a escola pública brasileira, ou mesmo de um técnico burocrata, que garanta as reformas e represente o Executivo.

Como afirma Peroni (2012), “a gestão democrática é parte do projeto de construção da democratização da sociedade brasileira" (p.26). Nesse contexto, indagamos se podemos considerar a avaliação prévia do desempenho do candidato à direção da escola nos moldes aprovados pelos municípios investigados, sob o ordenamento do PNE - um elemento que se constitua em uma perspectiva democrática. Cientes das limitações deste trabalho, sugerimos novas investigações e pesquisas que busquem, em diálogo com as redes públicas, a concretização de uma escola pública que coloque em cena critérios democráticos e participativos na seleção de seus diretores e no seu trabalho cotidiano.

Como desdobramentos da presente investigação, os próximos passos seguirão em busca de informações sobre o processo seletivo de diretores nas respectivas redes, como efeito da política municipal, buscando articular as determinações do plano de orientação da ação para a ação organizacional nas escolas públicas.

Recebido em: 11/03/2018 e Aprovado em: 26/04/2018

\section{Notas}

1 Dentre os 92 municípios que compõem o estado do Rio de Janeiro, 90 aprovaram seus Planos em 2015 e um em 2017 (Volta Redonda). O município do Rio de Janeiro, até o momento de conclusão deste texto, não havia aprovado seu Plano de Educação (AMARAL, 2016).

2 No período 2012-2016 a cidade foi governada por Alexandre Cardoso (PSD) e, em 2016, Washington Reis (PMDB) foi eleito para o período 2017-2021 na coligação "Rumo ao futuro" que reuniu PMDB/PSL/PPS/ PRP/PHS/PSB. 
3 Cabe destacar que o município do Rio de Janeiro ainda não teve aprovado seu Plano Municipal de Educação até o momento de finalização deste artigo.

\section{Referências}

AMARAL, Daniela Patti do. Mérito, desempenho e participação nos planos municipais de educação: sentidos da gestão democrática. Revista on line de Política e Gestão Educacional, v.20, n.03, p. 385404, 2016.

APERIBÉ. Lei. N. 667 de 28 de outubro de2016. Dispõe sobre a gestão democrática do ensino público de Aperibé. Aperibé, RJ, 2016.

BRASIL. Constituição da República Federativa do Brasil. Brasília: Senado. 1988.

. Lei n 13.005, de 25 de junho de 2014. Aprova o Plano Nacional de Educação - PNE e dá outras providências. Diário Oficial da União. Brasília, 2014.

. Lei n 9394, de 20 de dezembro de 1996. Estabelece as Diretrizes e Bases da Educação Nacional. Diário Oficial da União. Brasília, 1996.

CARMO. Lei N. 1852 de 25 de novembro de 2016. Dispõe sobre a instituição da gestão democrática na rede municipal de ensino de Carmo. Carmo, RJ, 2016.

DUQUE DE CAXIAS. Lei N. 2864 de 1 de novembro de 2017. Dispõe sobre a gestão democrática da educação pública no município de Duque de Caxias. Duque de Caxias, RJ, 2017.

FUNDAÇÃO MUNICIPAL DE EDUCAÇÃO DE NITERÓI. Edital N. 006/2017. Dispõe sobre o processo de consulta direta à comunidade escolar para a função de diretor e de diretor adjunto das unidades de educação da rede municipal de Niterói. Niterói, RJ, 2017.

GOMES, Ana Valeska Amaral. Gestão Democrática no Plano Nacional de Educação. Câmara dos Deputados, 2015. In: GOMES, Ana Valeska Amaral; BRITTO, Tatiana Feitosa. Plano Nacional de Educação: construção e perspectivas. Brasília: Edições Câmara/Edições Técnicas, 2015.

IGUABA GRANDE. Lei N. 016/2016 de 2 de agosto de 2016. Aprova o processo de gestão democrática no âmbito da rede municipal de educação de Iguaba Grande. Iguaba Grande, RJ, 2016.

LIMA, Licínio Carlos. Administração Escolar: estudos. Porto: Porto Editora, 2011.

LÜCK, Heloisa. Mapeamento de práticas de seleção e capacitação de diretores escolares. Fundação Vitor Civita: São Paulo, 2011.

MENDONÇA, Erasto Fortes. Estado Patrimonial e gestão democrática do ensino público no Brasil.

Educação \& Sociedade, Campinas: Cedes, ano 22, nº 75, 84-108, agosto de 2001.

PARO, Vitor. Gestão da Escola Pública: a Participação da Comunidade. Revista Brasileira de Estudos Pedagógicos. Brasília: INEP. v 73, n. 174, p.255-290, mai.-ago., 1992.

Gestão Democrática da Escola Pública. 4 ed. São Paulo: Cortez, 2016.

PERONI, Vera Maria Vidal. A gestão democrática da educação em tempos de parceria entre o público e o privado. Pro-Posições, Campinas: Unicamp, v. 23, n. 2 (68), p. 19-31, mai.- ago., 2012. 
PREFEITURA MUNICIPAL DE CABO FRIO. Resolução SEME N. 01 de 4 de janeiro de 2018. Cabo Frio, RJ, 2018.

PREFEITURA MUNICIPAL DE VALENÇA. Boletim Oficial. Edição N. 719 de 5 de novembro de 2015. Valença, RJ, 2015.

RIO DE JANEIRO. Secretaria Municipal de Educação. Resolução SME № 20, de 29 de setembro de 2017. Dispõe sobre o processo de Seleção de Gestores das Unidades Escolares da Rede Pública do Sistema Municipal de Ensino da Cidade do Rio de Janeiro. Rio de Janeiro, RJ, 2017.

SOUZA, Ângelo Ricardo de. Explorando e construindo um conceito de gestão escolar democrática. Educação em Revista. Belo Horizonte: UFMG, v.25; n.03; p.123-140, dez. 2009.

SUMIDOURO. Lei n. 1.142 de 15 de junho de 2016. Dispõe sobre a gestão democrática do ensino público de Sumidouro. Sumidouro, RJ, 2016. 